\title{
Teacher in the Mobile World
}

\author{
Jari Multisilta, Harri Keiho and Harri Ketamo \\ Tampere University of Technology, Pori Pohjoisranta 1IC, PO Box 300, FIN-28101 Pori, \\ Finland,jari.multisilta@pori.tut.fi,harri.keiho@pori.tut.fi,harri.ketamo@pori.tut.fi
}

\begin{abstract}
In this paper, we discuss wireless technologies and their role in educational applications and in teachers' everyday work. Today we already have powerful handheld devices that have wireless internet connection. History has shown that new technologies are often applied to merely do the same tasks as previous technologies. Handheld devices could provide teachers with new opportunities, but not by simply transforming current WWW content to handheld devices. What would be the best way to apply these technologies? In this paper we present the results from the study of Finnish youth as users of mobile phones. Based on this study we can say that Finnish youth are ready to adopt new mobile technologies for everyday use. In addition we discuss three current mainstream technologies, namely Wireless Application Protocol (WAP), Java MIDlet and PocketPC as examples of new mobile technologies and implementation platforms. In particular we try to focus on how teachers could apply these technologies in their teaching.
\end{abstract}

\section{INTRODUCTION}

Effective knowledge creation as well as support for life-long learning are among the biggest challenges in today's education and training. Mobility can be one approach to supporting life-long learning effectively in the context of place-independent information. Today, the typical distance learning environment includes a desktop computer and a modem-based Internet connection. This kind of setting does not offer full time-and-place independence. It can be achieved, however, by using wireless handheld devices such as mobile phones or handheld computers. The equipment available today makes it possible to create educational applications for demonstration purposes. For example, Ketamo (2002) has designed and

The original version of this chapter was revised: The copyright line was incorrect. This has been corrected. The Erratum to this chapter is available at DOI: 10.1007/978-0-387-35701-0_35 
experimented with geometry games for the Compaq Ipaq handheld computer.

However it is clear that mobile environments cannot offer all the services available, for example, in today's web-based learning environments. In Table 1 we characterise different distance learning environments and compare their features.

Table 1. Different distance learning environments and their features

\begin{tabular}{|c|c|c|}
\hline Environment & Example setup & Pros/Cons \\
\hline Desktop environment & $\begin{array}{l}\text { Desktop computer } \\
\text { - modem } \\
\text { - xDSL } \\
\text { - cable connection }\end{array}$ & $\begin{array}{l}\text { - Fast access } \\
\text { - Low cost } \\
\text { - Large screens } \\
\text { - "Normal" User Interface }\end{array}$ \\
\hline Laptop environment & $\begin{array}{l}\text { Laptop computer } \\
\text { - Modem } \\
\text { - GSM phone } \\
\text { - Wireless LAN (WLAN) }\end{array}$ & $\begin{array}{l}\text { - Place independent } \\
\text { - Slow connection } \\
\text { - Restricted operating time } \\
\text { - Limited network access } \\
\text { in WLAN }\end{array}$ \\
\hline Simple handheld & $\begin{array}{l}\text { Smartphone } \\
\text { - WAP phone } \\
\text { - Java enabled phone }\end{array}$ & $\begin{array}{l}\text { - } \text { Compact } \\
\text { - Limited applications } \\
\text { - Limited programming } \\
\text { - Limited processing power } \\
\text { - Limited screen size } \\
\text { - Restricted operating time } \\
\text { - Expensive data transfer } \\
\quad \text { rate } \\
\text { - Unstable }\end{array}$ \\
\hline Advanced handheld & $\begin{array}{l}\text { PDA, integrated PDA } \\
\text { - Compaq iPAQ + GSM } \\
\text { - Nokia Communicator } \\
\quad 9210\end{array}$ & $\begin{array}{l}\text { - Large scale of apps } \\
\text { - Advanced programming } \\
\text { - Acceptable screen size } \\
\text { - Expensive data transfer } \\
\quad \text { rate } \\
\text { - Restricted operating time }\end{array}$ \\
\hline
\end{tabular}

When designing educational material for the different environments listed above it would help if the author could use only one set of designing and publishing tools. This is not the case today. In Table 2 there is a comparison of different implementation tools that are available for each environment. If the teachers want to design material for mobile phones they have to use either the WML language or XHTML. XHTML can also be viewed in an ordinary desktop system (WWW browser), but there is not much XHTML based material available yet. A good possibility for the future will be small Java applications for mobile phones (called MIDlets).

In the next sections we discuss simple handheld and advanced handheld environments and present some examples of using them in education. Children could use (and are using) their mobile phones in every day school 
work especially in those countries where mobile phone penetration is high. Finland is one of the countries with high mobile phone penetration.

Table 2. Comparison of the implementation tools

\begin{tabular}{ll}
\hline \multicolumn{1}{c}{ Application environment } & \multicolumn{1}{c}{ Available tools } \\
\hline Web browser & - html pages \\
& -xhtml \& xml applications \\
WAP browser & - server side scripting \\
& - limited user side scripting \\
OS related software development & - wml scripting \\
& - server side scripting \\
& - EPOC SDK \\
Java enabled phones & - Microsoft CE SDK \\
\hline
\end{tabular}

\section{SIMPLE HANDHELD LEARNING ENVIRONMENTS}

An example of a simple handheld learning environment is a mobile phone with a WAP browser. Small applications can be programmed for simple handheld learning environments using, for example, WML or preferably XHTML. However, the user interface is very limited in simple handheld learning environments.

Wireless Application Environment (WAE) and Wireless Application Protocol (WAP) provide industry-wide standards and specifications for developing applications and services that operate over wireless communication networks (Mann, 2000; Niskanen, 2000; Wireless Application Protocol Forum Ltd, 1999a, 1999b). WAP is a major attempt to achieve universal Internet-based information access on wireless devices. WAP is now transforming towards XHTML based content.

Wireless Markup Language specification describes the markup language, WML, which include semantics, Document Type Definition (DTD), and encoding extensions. WML and XHTML are markup languages based on Extensible Markup Language (XML). XHTML support is available also in today's Web-browsers so some information can be viewed with a mobile phone or PC if it is in XHTML format.

WAP applications can be developed with special toolkits, for example the Nokia WAP Development Toolkit,' the Ericsson WAP development

\footnotetext{
${ }^{1}$ Nokia WAP Development Toolkit (http://www.nokia.com/wap/).
} 
$\mathrm{kit}^{2}$ or the UP.PHONE development environment. ${ }^{3}$ These toolkits include smart editors, phone simulators and a help system.

The screen size in a WAP phone is typically very small and existing WWW applications have to be converted to smaller screens and a simpler user interface.

\section{ADVANCED HANDHELD LEARNING ENVIRONMENTS}

An advanced handheld learning environment consists of a PDA computer and a wireless network connection. At best, these are integrated to a compact equipment such as Nokia Communicator 9210. The types of PDA equipment available today use several operating systems, namely Microsoft Pocket PC (Microsoft CE), EPOC or Palm OS. The features of these operating systems are compared for example in Tasker (2000). Typically the PDAs provide programmability not available in simple handheld learning environments.

Using EPOC operating system with the JAVA programming language is the easiest but still not an easy way to create a handheld learning environment with interactive features for advanced handheld devices. It is possible to make interactive learning environment applications by using pure EPOC programming, but at the moment EPOC SDKs are a little bit too complicated and inflexible. It is also possible to create distance learning applications by using the $\mathrm{C}++$ programming language with the EPOC operating system. This kind of programming is powerful and has versatile features but is a quite complicated way to create an application. Using pure $\mathrm{C}++$ language with the EPOC operating system makes the programmer often think that it is useless to re-invent the wheel. Programming advanced handheld devices using the EPOC operating system with $\mathrm{C}++$ and Java has much potential, but it is necessary to develop better programming environments and tools.

\section{THE REQUIREMENTS OF A GOOD LEARNING ENVIRONMENT IN A PDA}

On the basis of learning theories, the following properties are required from a good computer based learning environment: 1) The environment has to support the constructivist view of learning and thus it has to engage the

\footnotetext{
${ }^{2}$ Ericsson WAP Development Kit (http://www.ericsson.com/WAP/).

${ }^{3}$ UP.PHONE Development Environment (http://www.phone.com/products/upsdk.html).
} 
learner in active work. 2) The environment has to support social interaction in order to maintain co-operative or problem-based learning tasks. 3) Delivering information, tasks, objectives and feedback should be possible in the environment. 4) The environment should be open and able to be extended. It should be possible to bring other teaching materials, documents and tasks to the environment (Bereiter \& Scardamalia, 1993; Hopper, 1998; McGee \& Howard, 1998; Multisilta, 1999; Ruokamo \& Pohjolainen, 1998).

The advantages of PDAs can be seen especially in problem-based learning support. A portable mobile learning environment makes possible many different forms of communication with which the children can discuss learning problems or tasks even without seeing each other. The communication may be delivered for instance as traditional phone calls, image calls, literal text messages, on-line chat boards or off-line message boards. All these forms can be utilised between two or more partners. It is also possible to arrange a personal working area for each learner where the others can send messages and the learner can respond to them in whichever way he/she prefers. In this way, it is possible for the learner to have the opportunity of asking for advice from a teacher without the other participants even knowing it. This kind of 'facelessness' has been reported to have led to enhancement at least in university students' discussion (Marttunen, 1997). Traditional teacher-centered instruction is also possible in the mobile learning environment of this study, but it is assumed that the learning will be self-directed to encourage social knowledge construction between students (Ketamo, Alajääski \& Multisilta, 2000).

Though PDAs have certain benefits in educational usage, they still have obstacles in regard to software. The software of the PDAs has to be customized in order to utilise it for effective communication. Complete software packages can not be found yet. This can be seen, for example, in the video conferencing applications that are advertised. These applications are more or less library classes, which have to be embedded in some executable application. In the WWW environments, PDAs support only limited scripting. This creates many conflicts when trying to convert recent WWW applications to PDAs. This can be seen at the moment in IPAQ, where the 'window.open' system does not work at all and it is one of the most recent methods of controlling frames or windows in the WWW browser. This makes the use of frames difficult. Also, the screen size in a PDA is limited. In order to use existing web based learning environments, such as WebCT, the layout of the pages needs to be converted to support smaller screens. When these kinds of obstacles are solved, the usability of the PDAs will rise. 


\section{FINNISH YOUTH AS USERS OF MOBILE PHONES}

In this section we describe the results of the recent study of the habits of using mobile phone among Finnish youth. The study has been repeated three times in the Satakunta region in the years 2000-2002 and it gives valuable information for the teachers and parents about how mobile phones are used among children. The questionnaire was implemented as a web form and the form address was emailed to all schools in the Satakunta region. The students in different age groups were asked to go to the web and fill in the questionnaire. The answers were recorded to the server automatically (using cgi-scripts). The size of the sample is over 2300 students in total, $n=1055$ (year 2002), 657 (2001) and 717 (2000).

The percentage of children who own their own mobile phone can be seen in Figure 1. The number has increased rapidly during the last two years. It can be seen that the percentage is significantly high for 13 years old and above. During the last year (2001-2002) the percentage was increasing only in the group of the youngest children.

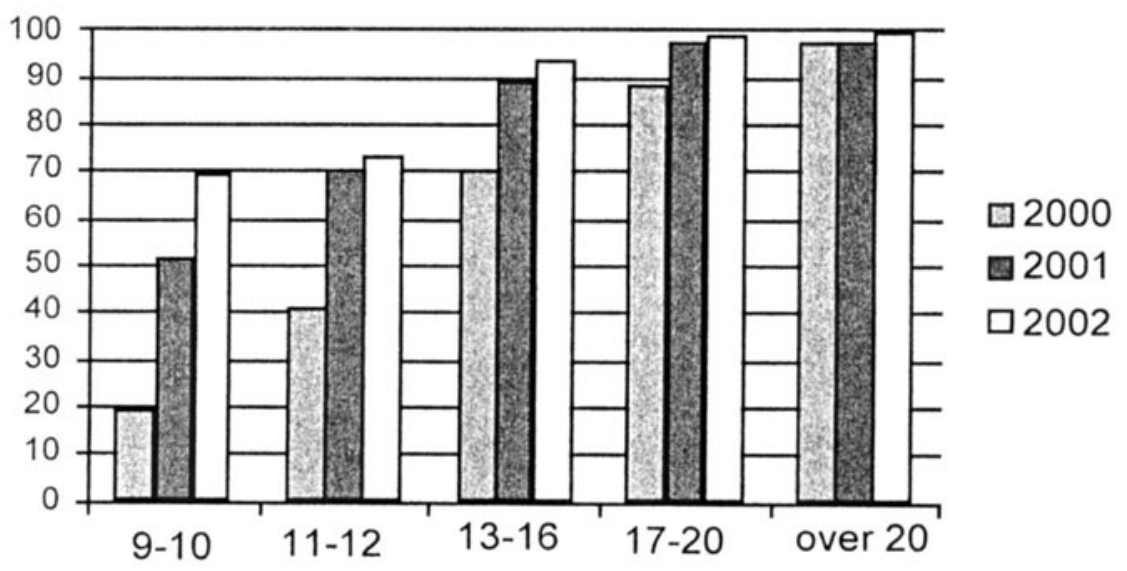

Figure 1. The percentage of children who own a mobile phone in different age groups (vertical axis shows percentages; horizontal axis shows age groups)

Figure 2 shows the number of calls children said they make with their mobile phones in a month. The figures are quite high. We do not expect that children actually do make as many real calls. It is widely known that children sometimes make a call that is not intended to be answered. For example, a child could call to her school friend and let the phone ring once. This means "goodnight". Two rings could mean "call me". This is predicated on the fact that the caller number is saved to the phone's memory. 


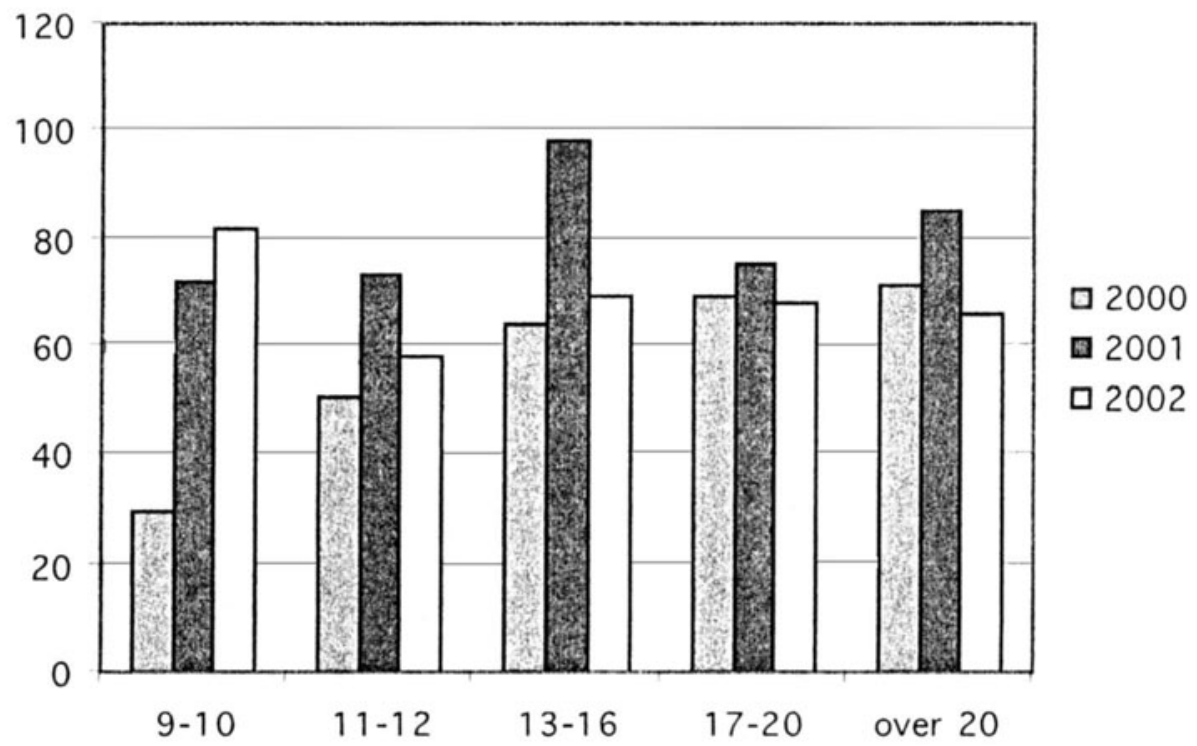

Figure 2. The number of calls made in a month by different age groups (vertical axis shows number of calls; horizontal axis shows age groups)

The children sent quite a number of short text messages (SMS) in a month (see Figure 3). However, the number of SMSs has decreased from year 2001 when the number of sent SMSs was much higher. The new Multimedia Messaging Services (MMS) have just been launched in Europe. It will be interesting to see if young people will adopt these services as they did with SMS.

The phones the children own are typically at most one year old (see Figure 4). This means that children have the newest models available on the market. With these new phones the children are ready to use the latest applications (based on MMS or Java technology).

The most important facts when buying a new phone are technical features, price and the brand (Fig. 5). In this study we did not ask what brands the children use - in Finland, however, Nokia has the biggest market share and they do have phones with features attracting young people. It is interesting that children want to buy their phones themselves - the phones do not come from 'second-hand' stores or as presents. 


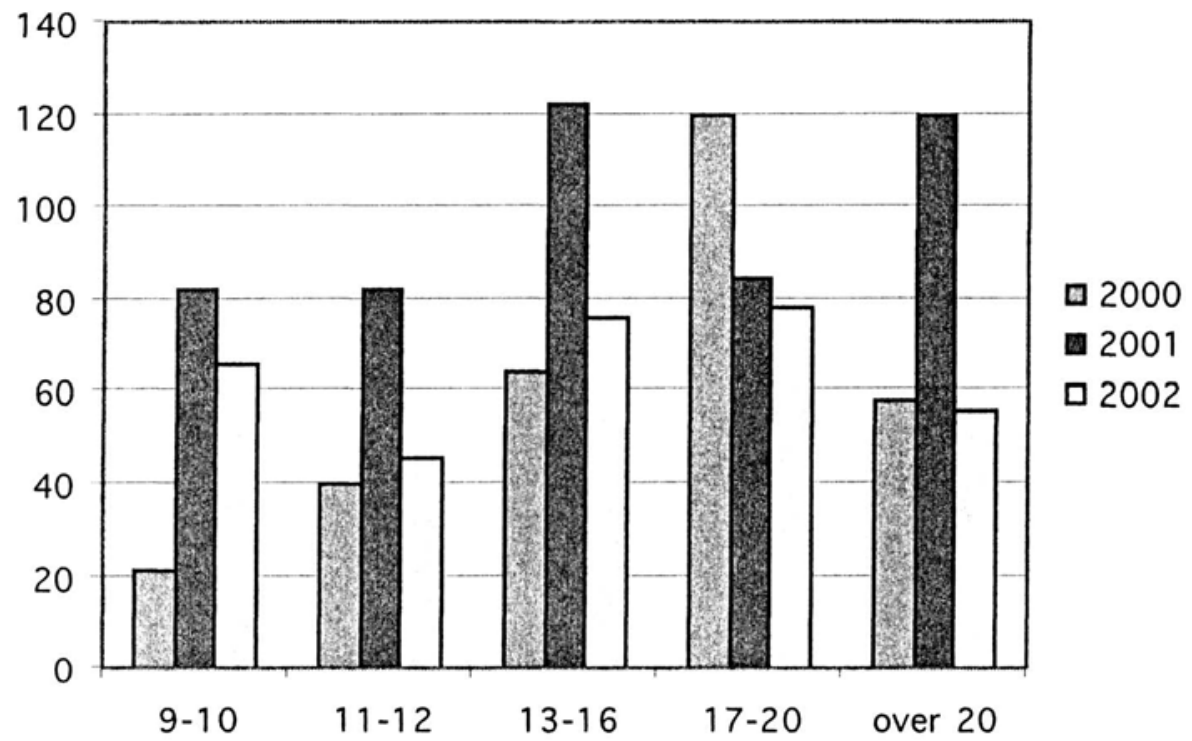

Figure 3. The number of sent text messages (SMS) per month (vertical axis shows number of text messages sent; horizontal axis shows the age groups)

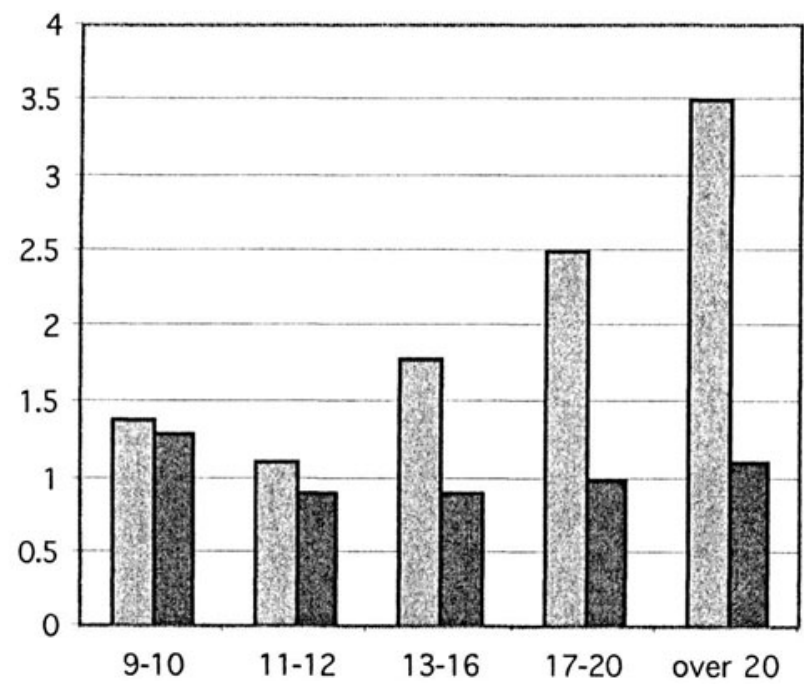

$\square$ Have owned a mobile phone (years)

四 The age of the current phone (years)

Figure 4. How long the mobile phoned have been owned (vertical axis shows the number of years; horizontal axis shows age groups 


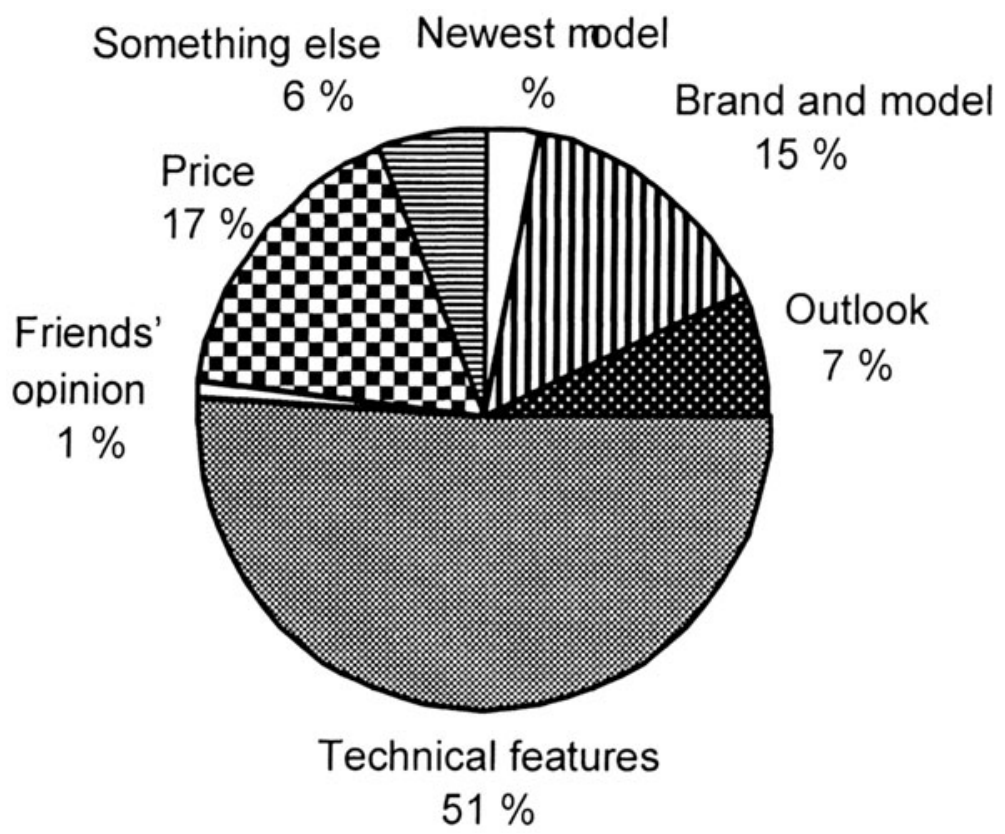

Figure 5. The most important criteria when buying a mobile phone

\section{CONCLUSIONS}

At its best, learning with the Internet makes learning even more effective than the traditional teaching methods used in the normal classroom. What is needed is some imagination from the teachers, programmers and other developers of the technology - and pedagogical views that ensure that the learning via the Internet is effective and motivating for both students and teachers. However, there is one important thing to bear in mind: for a teacher and students the computer is always just a tool; the main focus is and will be on the content of the course and the learning processes of the students. We should also take particular care that students and learners in networked learning environments develop their social skills.

In this paper we have discussed the role of wireless handheld devices in educational applications from the point of view of the production of content. In general there are two different types of handheld learning environment, namely simple and advanced. Simple handheld learning environments include WAP phones. Advanced handheld learning environments are, for example, PDA equipment. The advantages of PDAs can be seen especially in problem-based learning support. A portable mobile learning environment 
makes possible many different forms of communication with which the children can discuss learning problems or tasks even without seeing each other. Though PDAs have certain benefits for educational usage, there are still obstacles in regard to software. The software of the PDAs has to be customized in order to utilise them for effective communication. Complete software packages can not be found yet. Based on our study of Finnish youth, children in Finland are ready to apply these wireless technologies. What is needed is pedagogically meaningful applications for mobile devices.

\section{REFERENCES}

Bereiter, C. \& Scardamalia, M. (1993). Surpassing Ourselves. An Inquiry into the Nature and Implications of Expertise. Chicago, IL: Open Court.

Hopper, M. (1998). Assessment in www-based learning systems: Opportunities and challenges. Journal of Universal Computer Science, 4. Retrieved from http://www.iicm.edu/jucs_4_4/assasment_in_www_based/paper.html].

Keiho H., Lahti J. \& Multisilta J. (2000). Teaching WAP technology as a part of a multimedia course. Proceedings of the ED-MEDIA 2000, Montréal, Quebec, Canada

Keiho, H., Lahti, J. \& Multisilta, J. (2000). Teaching WAP technology as a part of multimedia course. Proceedings of 16 th IFIP World Computer Congress 2000, Beijing, China.

Ketamo, H. (2002). User and Platform Adaptation in Web-based Learning Environments. PhD thesis, Tampere University of Technology Publications 381, Tampere, Finland.

Ketamo, H., Alajääski, J. \& Multisilta, J. (2000) eLearning - The Next Generation: A Vision about Mobile Technologies in Elementary Education. Paper submitted to WCCE: The 7th World Conference on Computers in Education, Copenhagen, Denmark.

Mann, S. (2000). Programming Applications with Wireless Application Protocol. The Complete Developers Guide. New York, USA: John Wiley \& Sons.

Marttunen, M. (1997). Electronical mail as a pedagogical delivery system: An analysis of the learning of argumentation. Research in Higher Education, 38(3), 345-363.

McGee, S. \& Howard, B. (1998). Evaluating educational multimedia in the context of use. Journal of Universal Computer Science, 4. Retrieved from http://www.iicm.edu/ jucs_4_3/evaluating_educational_multimedia_in/paper.html].

Multisilta, J. (Ed.) (1999). Open learning environments - Old wine in new wineskins? In Proceedings of AI-ED, What Do we Know of Open Learning Environments? France: LeMans.

Niskanen P. (2000). Inside WAP. Helsinki, Finland: IT Press.

Ruokamo, H. \& Pohjolainen, S. (1998). Pedagogical principles for evaluation of hypermediabased learning environments in mathematics Journal of Universal Computer Science, 4. Retrieved from http://www.iicm.edu/jucs_4_3/pedagogical_principles_for_evaluation/ paper.html

Tasker, Martin et al (2000) Professional Symbian Programming. Birmingham, UK: Wrox Press Ltd.

WAP Forum (2000). Retrieved January 24, 2000 from http://www.wapforum.org/

Wireless Application Protocol Forum Ltd (1999a). Official Wireless Application Protocol. The Complete Standard with Searchable CD-ROM. New York: John Wiley \& Sons.

Wireless Application Protocol Forum Ltd (1999b). DTD. Retrieved January 31, 2000 from http://www.wapforum.org/DTD/wml.xml 